\title{
Sobre a "conveniência" da escola
}

\author{
Marisa Vorraber Costa \\ Universidade Federal do Rio Grande do Sul, Programa de Pós-Graduação em Educação \\ Universidade Luterana do Brasil, Programa de Pós-Graduação em Educação
}

Mariangela Momo

Universidade Federal do Rio Grande do Norte, Departamento de Educação

Um dos debates acalorados da atualidade, tanto no campo específico da educação como na sociedade em geral, ocupa-se da crise da educação escolar e da escola como instituição. Embora este artigo não trate especificamente dessa problemática, interessa-nos considerar a existência dessa discussão, na medida em que ela coloca em pauta o papel e o lugar da escola no mundo em que vivemos.

Nas abordagens realizadas por vários autores brasileiros contemporâneos constantes do livro de entrevistas intitulado A escola tem futuro? (Costa, 2007a), ficam evidentes distintas óticas e variadas formas de entender a condição da escola hoje, assim como, em muitos pontos, convergem as possibilidades, dúvidas e riscos vislumbrados para seu futuro. Arroyo (2007), um dos entrevistados, diz que a escola ter ou não futuro é algo que depende do que acontecerá com questões mais amplas na sociedade, como os movimentos sociais, as transformações da democracia, a própria democratização do poder e das políticas e recursos públicos. Moreira (2007) aponta para a necessidade de considerar questões do âmbito mais amplo da sociedade, como as pedagogias da mídia, que podem colaborar para se pensar sobre problemas específicos do campo da educação, como o currículo escolar. Ele destaca que "processos culturais bastante complexos [estão] ocorrendo fora da escola e afetando a escola” (p. 59). Veiga-Neto (2007), por sua vez, examina como a escola se tornou o que é a partir de seu envolvimento com a sociedade em que está inserida e argumenta que podemos entender melhor, através da escola, as transformações do mundo de hoje. Na mesma direção, Costa (2007b), ao introduzir as conversações do livro, destaca que "tudo que acontece na escola tem fios e tramas dentro e fora da escola. Esquecer isso, ou negligenciar isso, tem consequências sérias” (p. 68).

Podemos dizer que a crise da escola tem sido considerada por vários pesquisadores uma expressão dos embaraços que enfrenta ao prosseguir no cumprimento de seus desígnios, tal como foram esboçados no projeto filosófico, sociopolítico e cultural da modernidade. Admite-se que há, hoje, um descompasso entre a escola e os novos tempos. Parece que ela não tem conseguido assegurar a formação adequada, seja para os que por ela passam e têm dificuldades, seja para os que nela foram ou são bem-sucedidos, atingindo o mais alto grau de escolaridade. Além disso, se um dos objetivos importantes da escola moderna é a civilidade - a 
formação do cidadão educado e apto a conviver em sociedade -, nos tempos atuais ele parece desgastado, uma vez que considerável proporção de estudantes se movimenta habilmente no mundo das transgressões e da delinquência, pratica violências de todo tipo, agride, rouba e trafica. Como bem argumenta Arroyo (2007), “aprender [e ensinar] a ser humano é, sem dúvida, mais exigente para a pedagogia em tempos de globalização, de barbárie e exclusão” (p. 142-143).

São gritantes os indícios de que a escola da atualidade está impregnada de marcas das sociedades contemporâneas, eivadas de ambivalências. Assim como as autoras e os autores entrevistados na obra referida apontaram evidências de sua crise, na conversa inicial entabulada pela entrevistadora é mencionado um conjunto de "utilidades" da escola. Parece que ela não ocupa apenas um lugar especial no imaginário popular e na configuração dos espaços-tempos da materialidade cotidiana da vida urbana (ou mesmo rural). Ela tem sido também importante protagonista na movimentação da economia das sociedades globalizadas regidas pelo mercado (Costa, 2007b), seja como cliente das redes de serviços e artefatos tecnológicos, como consumidora de produtos novidadeiros (pacotes instrucionais, testes padronizados, materiais didáticos e mobiliários), seja como espaço de mercantilização de todo tipo de produtos, inclusive de cérebros para as "economias fundadas no conhecimento” (Robertson, 2006c). Ela também tem sido rentável inspiradora de argumentos literários em narrativas que acionam as emoções e agitam bilheterias da indústria cinematográfica, arregimentam audiências para a mídia televisiva ou seduzem leitores em revistas e livros. A telenovela Rebeldes, o sucesso midiático High School Musical e o fenômeno literário Harry Potter são exemplos bem atuais de narrativas em que a escola é componente importante da trama.

Já faz um bom tempo que alguns autores da área da educação e de outras vêm apontando para a "mercantilização" da escola e da educação ${ }^{1}$ e sua inequí-

1 Susan Robertson (2006, 2006a, 2006b, 2006c, 2006d, 2007, 2007a), Gustavo Fischmann (2004), Gustavo Fischmann e Ricardo Costa (2004), e Nora Krawczyk (2005) são alguns desses voca conexão com políticas neoliberais regidas pela atenção primordial às movimentações do mercado ${ }^{2}$. Tal faceta é visível tanto nas estratégias de marketing que transformaram a própria educação em mais uma commodity lucrativa a circular nas sociedades de hoje como na reconfiguração dos espaços escolares, agora verdadeiros shopping centers onde se pode encontrar de tudo, de salões de estética e locadoras de vídeo a livrarias, farmácias e boutiques, não esquecendo que agências bancárias, cantinas, restaurantes e quiosques de fast-food, ao lado de centros especializados em fotocópias e editoração gráfica, bem como redes de transporte alternativo, já ocupam o espaço escolar no Brasil há mais de duas décadas. Não são poucas as escolas com grifes próprias, nas quais camisetas, uniformes, cadernos, mochilas e até notebooks com sua logomarca estampada fazem parte do "pacote" a ser adquirido pelo aluno-cliente. Essa face mercantilizada, contudo, não é visível apenas naquelas frequentadas pelas camadas mais bem aquinhoadas da população. Com peculiaridades e variantes que instigam nossa curiosidade e interesse, facetas desse fenômeno têm-se tornado visíveis em nossas pesquisas ${ }^{3}$, inclusive nas

autores cujos artigos sobre a mercantilização da educação e do conhecimento contribuem para vislumbrar mais uma das faces do que problematizamos neste texto. Naomi Klein (2004) é outra pesquisadora que analisa a presença da publicidade nas escolas e universidades dos Estados Unidos e Canadá e demonstra que a tirania das marcas tem tornado esses espaços parecidos com centros comerciais.

${ }^{2}$ A tese de doutorado de Vera S. Gerzson (2007), intitulada A mídia como dispositivo da governamentalidade neoliberal - os discursos sobre educação nas revistas Veja, Época e IstoÉ, constitui instigante exemplo de análise que mostra a mídia sugerindo concepções e práticas de educação para a sociedade, todas atreladas às políticas neoliberais, e incumbindo a educação escolar de preparar os estudantes para a produtividade máxima no imenso mercado em que se transformou o mundo globalizado.

3 Trata-se dos projetos desenvolvidos por Marisa Vorraber Costa e apoiados pelo CNPq, intitulados Quando o pós-moderno invade a escola - um estudo sobre novos artefatos, identidades $e$ práticas culturais (2004-2007) e Consumo, mídia e espetáculo na 
escolas localizadas nas periferias onde se concentram as populações pobres dos grandes centros urbanos. $\mathrm{O}$ mundo globalizado regido pelo mercado imprime suas marcas por toda parte.

O espaço escolar transformou-se em um rentável negócio. A tal ponto isso ficou evidente que as grandes corporações empresariais anseiam por associar e fazer circular sua marca, seu logo, no circuito escolar (Klein, 2004). O presente artigo esboça-se nesse cenário, mas volta-se para outras nuances, para os indícios de que a "conveniência” da escola ultrapassa o interesse mercantil imediato e se projeta como estratégia direcionada à variada gama de propósitos sociopolíticos, econômicos e culturais.

\section{A cultura e a escola como recurso}

No intento de procurar mostrar a "conveniência” da escola, recorremos especialmente à teorização de George Yúdice ${ }^{4}$ (2004), um dos estudiosos dedicados à análise das sociedades e da cultura contemporâneas, cuja obra recente - A conveniência da cultura: usos da cultura na era global - trata de mostrar e problematizar a incorporação da cultura ao aparato produtivo como recurso do crescimento econômico, fórmula para solução de conflitos sociais e como criadora de novas oportunidades de trabalho.

Vários autores têm-se dedicado a interpretar as compreensões e as práticas de cultura atravessadas pelas transformações verificadas especialmente nos

cena pedagógica - investigando relações entre escola e cultura contemporânea (2007-2010); e da tese de doutorado de Mariangela Momo, intitulada Mídia e consumo na produção de uma infância pós-moderna que vai à escola (UFRGS, 2007).

${ }^{4}$ George Yúdice é professor titular do American Studies Program e do Departamento de Espanhol e Português da Universidade de Nova York (New York University - NYU), diretor do Privatization of Culture Project, um centro de investigação de políticas culturais, também da NYU, e do Centro de Estudios Latinoamericanos y del Caribe. É um dos principais teóricos mundiais sobre a indústria cultural e uma referência nos estudos culturais sobre América Latina. meados da segunda metade do século XX, e alguns, como Jameson (1996), consideram ser cultural a própria lógica do capitalismo contemporâneo ${ }^{5}$. Yúdice (2004) chama a atenção em sua análise para a complexidade de tal questão, situada, hoje, "na interseção das agendas da economia e da justiça social” (p. 35).

De acordo com Yúdice (2006), em meio ao numeroso conjunto de significados acumulados e negociados nos usos da palavra cultura, ela refere-se a "processos simbólicos que delimitam um dentro e um fora hierarquizados” (p. 11) em que “o que está em jogo é a colocação de fronteiras” (p. 12). Assim, “a cultura, além de ser transcendência, enaltecimento e identidade compartilhada, é também delimitação, que apoia hierarquias e relações de poder” (p. 12). É dessa face que emergem os efeitos constitutivos da cultura que vão moldar identidades, imagens, sentimentos, práticas sociais e condutas individuais e coletivas. Nos períodos críticos, em que conflitos de interesses estão em jogo, as relações entre cultura, sujeitos e sociedade alteram-se e novas possibilidades de ação surgem, operando disjunções nos processos de delimitação. Os fluxos globais verificados no século XX estariam configurando um desses períodos.

Segundo seu entendimento, emerge contemporaneamente um uso para a cultura que implica novos significados. Essa nova forma de operar com a cultura é identificada mediante o emprego da expressão "a cultura como recurso":

\section{A noção de cultura como recurso pressupõe seu gerenciamen- to, uma perspectiva que não era característica nem da alta cul- tura nem da cultura cotidiana no sentido antropológico. E, para complicar ainda mais a questão, a cultura como recurso circula globalmente, numa velocidade crescente. Consequentemen- te, seu gerenciamento, que por meio século foi dirigido em escala nacional na maioria dos países da Europa, da América}

\footnotetext{
${ }^{5}$ Fredric Jameson (1996), conhecido crítico marxista
} norte-americano, é um dos autores que desenvolve uma análise enciclopédica da cena cultural contemporânea para demonstrar a centralidade da cultura pós-moderna na lógica que orienta a fase tardia do capitalismo. 
Latina e nos Estados Unidos [...], é agora coordenado tanto local quanto supranacionalmente por corporações e pelo setor não-governamental internacional (por exemplo, UNESCO, fundações, ONGs). (Yúdice, 2004, p. 17)

Na obra referida, o autor expõe a maneira pela qual diferentes grupos - ativistas nativos, naçõesEstados, organizações não governamentais e outros - passaram a ver a cultura como um valioso recurso para investimentos, contestações e outras finalidades e interesses. Sua argumentação provê uma grande variedade de exemplos de usos da cultura como recurso, e um de seus focos é procurar entender o que a transformação da cultura em recurso ensina sobre nosso período histórico.

O que pretendemos evidenciar neste artigo sobre a conveniência da escola parece resultar daquilo que Yúdice (2004) identifica como força performativa, “entendida como os condicionamentos, as imposições e pressões exercidas pelo campo multidimensionado do social e pelas relações institucionais” (p. 64). Ele utiliza a noção de performatividade $e^{6}$ para designar esse modo como "o social é cada vez mais praticado" (p. 49) e como isso se constitui em "lógica fundamental da vida social de hoje” (p. 50).

Em sua análise, essa noção colabora para o entendimento de que a cultura é produzida e regulada por forças performativas que a condicionam, impõem e pressionam. Performatividade refere-se aos processos pelos quais "identidades e entidades de realidade social são constituídas pelas repetidas aproximações de modelos (ou seja, o normativo), bem como por aqueles 'resíduos' ('exclusões constitutivas’) que são insuficientes” (Yúdice, 2004, p. 53). Dito de outro modo, a força performativa pode ser entendida como a "obrigação" por desempenhar ou desviar dos modelos sugeridos. O autor também alerta para o fato de que a globalização proporciona o contato mútuo entre culturas diferentes, o que faz com que

${ }^{6}$ Yúdice utiliza esse conceito inspirado de alguma forma no uso da teoria da performatividade, de Judith Butler, como um ato discursivo performativo, um ato que produz o que nomeia. aumente o questionamento das normas e instigue a performatividade.

Yúdice demonstra que as lutas em torno da cultura - um recurso a ser disputado - tomam formas diferentes, dependendo do campo de forças nas quais operam: "a força de performatividade [pode ser] compreendida e experimentada de formas diferentes em sociedades diferentes” (Yúdice, 2004, p. 69). Essas diferenças têm a ver com campos de força diferentes gerados "por relações dispostas diferentemente entre as instituições estatais e a sociedade civil, o judiciário, a polícia, as escolas e universidades, a mídia, os mercados de consumo etc.” (idem, ibidem, p. 69). Yúdice ressalta como o neoliberalismo das economias latino-americanas, incluindo as privatizações, condiciona tipos de performatividade nos países latinoamericanos (p. 113), num estilo que ele considera ser especificamente estadunidense de relações sociais, e que ele denomina de "força performativa".

Sendo a escola um lugar na cultura, um lugar onde a cultura circula, onde culturas se encontram e negociam, onde se produz e consome cultura, a escola também começa a ser posicionada em relação a esse novo jeito de a cultura operar e também ensina muito sobre nosso período histórico e sobre novas funções e significados da escola na ordem contemporânea orientada para e pelo mercado. É nessa direção que a análise de Yúdice ajuda nesse intento de salientar a “conveniência” da escola. Ela é uma instituição que ocupa um espaço físico privilegiado de confluência de pessoas, de reunião, de encontros duradouros e sistemáticos. Há escolas por toda a parte, em distribuição geográfica pelos territórios nacionais que é atravessada por várias racionalidades político-sociais, fazendo dela um centro aglutinador de todo o tipo de sujeitos. Ela atrai, reúne e mantém esse lugar de encontro preservado, propício para a circulação de significados e para ações de governamento ${ }^{7}$. Sobretudo pelo seu aparentemente

${ }^{7}$ Empregamos o termo na acepção foucaultiana, que o distingue das ações de governo praticadas pelo Estado. Nesse caso, governamento se refere ao exercício de ações de governo praticadas por vários agentes (pais, professores, ONGs, família, igrejas, instituições 
inesgotável capital simbólico como agência cultural, ela é detentora de uma inabalável legitimidade institucional no panorama social. Consideramos que aquilo que começamos a observar na escola, nas formas como ela vai sendo articulada nas práticas sociais, políticas e econômicas da atualidade, é, então, intrínseco e imanente a esse jeito de a cultura operar no mundo de hoje.

\section{Cultura, performatividade e a conveniência da escola}

Em uma tentativa de operar com os conceitos buscados na teorização de Yúdice, realizamos um exercício analítico sobre três projetos sociais - Você Apita $^{8}$, Tim Música nas Escolas ${ }^{9}$ e Escola Aberta ${ }^{10}-$ que consideramos expressivos dessa forma como empresas, organizações públicas e iniciativas da

públicas, organizações privadas, corporações empresariais etc.).

${ }^{8}$ Você Apita é um projeto de iniciativa da empresa automobilística Fiat, em colaboração com organizações governamentais e não-governamentais, que ocorreu em escolas públicas brasileiras durante os anos 2002, 2003 e 2004. O projeto desenvolveu-se inserido nas aulas regulares de diversas disciplinas do ensino fundamental e médio, tendo como foco quatro temáticas: Direitos fundamentais, Meio ambiente, Questões de convivência e Mobilidade. Disponível em: http://www.fiat.com.br/br/afiat/voceapita. jsp. Acesso em: 13 jun. 2007.

${ }^{9}$ Tim Música nas Escolas é um projeto da empresa de telefonia Tim, que teve início em 2003 e em 2007 ainda prosseguia em escolas públicas brasileiras, no formato de oficinas de musicalização. Disponível em: http://www.valoronline.com.br/vsocial/pdf/2006/ TIM_relacoes_comunidade.pdf. Acesso em: 13 jun. 2007.

${ }^{10}$ O programa Escola Aberta foi criado por um acordo de cooperação entre o Ministério da Educação e a Unesco e promove, desde 2004, junto com 68 secretarias municipais de educação e cinco secretarias estaduais, a abertura, nos finais de semana, das escolas públicas localizadas em zonas urbanas de risco e vulnerabilidade social, para que a população possa utilizar os espaços da escola e participar de "atividades de cultura, esporte, lazer, geração de renda, formação para a cidadania e ações educativas complementares”. Disponível em: http://www.fnde.gov.br/home/index.jsp?arquivo=/ escola_aberta/escola_aberta.html. Acesso em: 13 jun. 2007. sociedade civil se articulam com a cultura e a educação escolar para fazer os mercados globalizados se movimentarem, mas não apenas em seus próprios interesses, embora esses persistam no topo das prioridades. Embora projetos semelhantes continuem sendo realizados nas escolas públicas municipais de Porto Alegre, esses foram escolhidos porque aconteceram em escolas onde pesquisamos entre os anos de 2004 e 2007. Nosso intento não é dissecar os projetos, mas apontar neles evidências da cultura como recurso e da “conveniência” da escola nesse processo.

Nessa nova "organização”, o próprio "mundo" parece aproveitar o poder simbólico da escola e arranjar um "lugar” para ela. Ou seja, a escola parece ser uma das importantes instituições para a composição da força performativa, que também pode ser entendida como "o espetáculo” proporcionado pela articulação entre distintos setores (mídia, mercado, igrejas, escolas, ONGs etc.) no gerenciamento da cultura. Segundo Yúdice (2004), o gerenciamento da cultura faz-se necessário na medida em que ela passa a ser vista como um recurso capaz de resolver problemas que antes eram (ou procuravam ser) equacionados pela economia ou pela política, ou seja, problemas que eram tidos como próprios desses domínios.

De fato, quando instituições poderosas como a União Europeia, o Banco Mundial, o Banco Interamericano de Desenvolvimento (BID), as maiores fundações internacionais e assim por diante começam a compreender a cultura como uma esfera crucial para investimentos, a cultura e as artes são cada vez mais tratadas como qualquer outro recurso.

(Yúdice, 2004, p. 30)

Dessa forma, como qualquer outro recurso (por exemplo, recursos naturais), há um cálculo de interesses para determinar o valor de uma ação no investimento em cultura ${ }^{11}$. Não é o mérito da cultura

${ }^{11}$ Um aspecto interessante é que, se antes a arte não se dobrava ao conceito de utilidade, agora de certa forma ela é produzida para a utilidade. O próprio Yúdice (2005) afirmou, em entrevista, que, embora tenha sido sempre muito crítico em relação ao uso da arte 
em si que define se ela é digna ou não de receber investimentos, "o modelo de financiamento cultural precisa ser limitado a segmentos específicos da cultura porque a demanda de recursos é grande e porque somente aqueles que podem gerar retorno serão financiados" (Yúdice, 2004, p. 32). Parece que a educação (um bem tido como universal) é um dos segmentos que, entre outros fatores, por abranger grande parte da população mundial, garante alguma espécie de retorno. Entre os retornos possíveis estão os incentivos fiscais, a comercialização institucional ou o valor publicitário e "a conversão de atividade não comercial em atividade comercial” (Yúdice, 2004, p. 32).

Precisamente esse tipo de retorno pode ser constatado no caso em que uma atividade escolar - como a caminhada anual de alunos de escolas de Porto Alegre pelas ruas da cidade em comemoração à Proclamação da Independência do Brasil - é convertida em uma "atividade comercial”, na qual a Fiat "imprime" seu logo e garante publicidade para a marca e para sua concessionária San Marino, divulgando seu protagonismo no projeto Você Apita e acumulando capital simbólico ao associar-se a ações educacionais (ver figuras 1 e 2).

Fazendo proliferar os significados edificantes dessas ações, notícias circulam na internet e na mídia em geral, dando visibilidade à participação social das empresas. A matéria que segue, encontrada na grande rede, destaca a participação da Fiat e de sua concessionária na performance educativa do Você Apita:

Junto com um boneco gigante, mascote da Concessionária San Marino, parceria da ação educativa em Porto Alegre-RS, as crianças da EMEF Wenceslau Fontoura participaram da caminhada cívica tradicional da cidade. Escolas do município todo estavam presentes para celebrar o feriado que comemora a independência do País. Diante da comunidade e de autoridades da cidade - entre eles o representante do

para fins práticos, hoje está pensando de forma diferente e já admite que é inevitável o uso da cultura como recurso. Nesse caso, diz ele, “o único jogo que existe é o do gerenciamento, da gestão dos recursos”. A arte será colocada em um museu para contribuir com a economia de uma cidade, e a única forma de se aferir ganhos sociais com isso é participar ativamente do gerenciamento desse uso da cultura. prefeito e a secretária de Educação -, os alunos participantes do Você Apita distribuíram fitinhas com a mensagem "paz no trânsito”. Eles portavam faixas, cartazes e placas em forma de apitos com dizeres enfatizando o protagonismo e a segurança no trânsito. ${ }^{12}$

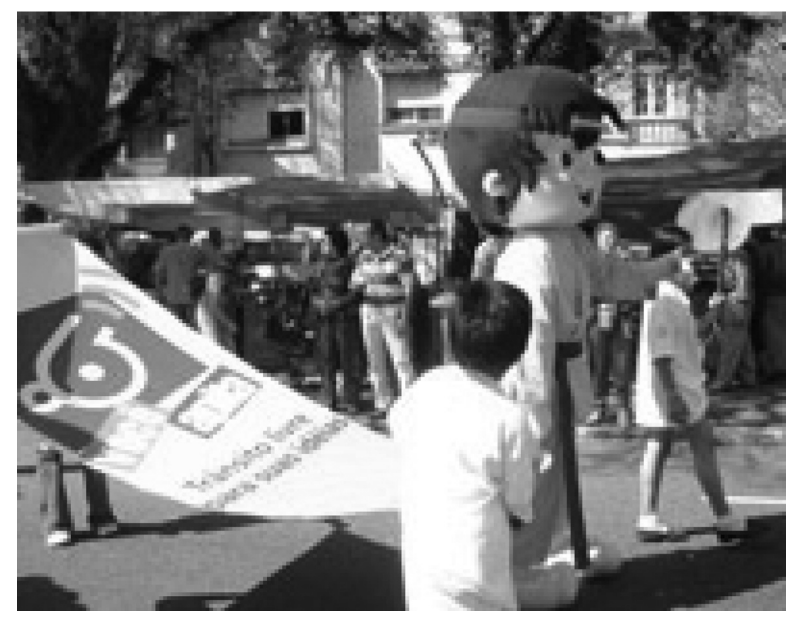

Figura 1: Boneco mascote e crianças do Você Apita chamam a atenção durante desfile cívico pela cidade

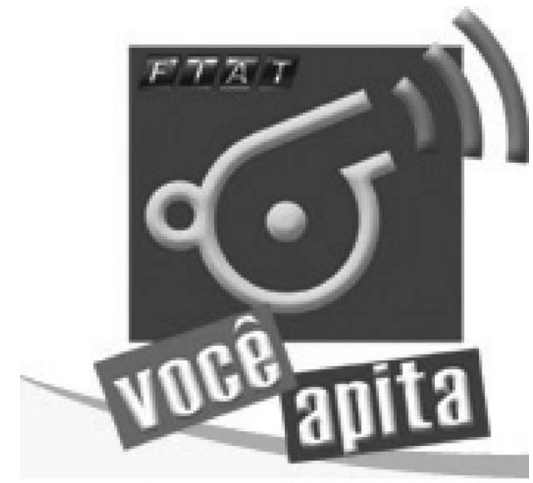

Figura 2: Logotipo do projeto Você Apita

Quando a Fiat e a Tim investem nesses projetos específicos - Você Apita e Tim Música nas Escolas - o cálculo de interesses é realizado com dados quantitativos, como o número de municípios envolvidos, o número de escolas e alunos que atingem. ${ }^{13}$ Tais projetos

12 Disponível em http://www.voceapita.com.br/noticias/ visualizanoticia.asp?idn=161. Acesso em 17 fev. 2006.

${ }^{13}$ A contabilidade do projeto Você Apita durante o ano 2003 somava 391 escolas, 26.000 alunos, 2.074 professores, 456 colabo- 
garantem a associação de suas marcas à responsabilidade social. A Tim, por exemplo, sublinha sua performatividade declarando que investe na música - paga os instrumentos musicais, os professores de música, as passagens para os estudantes se locomoverem até as oficinas e ainda oferece uma ajuda para as famílias - com o objetivo de "resolver" problemas sociais. Como bem argumenta Yúdice (2004), “hoje em dia é quase impossível encontrar declarações públicas que não arregimentem a instrumentalização da arte e da cultura” (p. 27). A nota na mídia confirma isso:

\begin{abstract}
A Tim foca seu apoio em projetos socioeducativos que utilizam a música como linguagem. O principal projeto apoiado pela empresa é o Tim Música nas Escolas, cujo objetivo é possibilitar a crianças e adolescentes de 7 a 15 anos o acesso a diferentes modos de aprendizagem e de atuação na sociedade, utilizando-se da linguagem universal da música. ${ }^{14}$
\end{abstract}

Yúdice (2004) ressalta que a importância da articulação da cultura na solução de problemas sociais não é nova, pois há muitos registros de programas de terapia artística para deficientes mentais ou para presidiários. Contudo, parece que a cultura não chegava a ser vista como "terapia adequada para disfunções sociais como o racismo ou o genocídio” (p. 28). Hoje, o programa Escola Aberta, ao declarar como um de seus objetivos contribuir para a redução da violência na comunidade escolar e para a construção de uma cultura da paz, ${ }^{15}$ mostra uma expansão do espectro de problemas sociais a serem enfrentados com o uso da cultura.

radores, 2.130 ações em 18 cidades. O Tim Música nas Escolas em 2006 estava presente em oito cidades do Brasil e envolvia 15 mil alunos de escolas públicas. E o programa Escola Aberta possuía como meta inicial alcançar a participação mensal de 1,2 milhão de pessoas das comunidades escolares em todas as regiões do país. Informações disponíveis nos sites dos referidos projetos.

${ }^{14}$ Disponível em: http://www.tim.com.br/portaltim/home/0,16 06,18O0O11O45O282O3647,00.html. Acesso em: 17 fev. 2007.

15 Disponível em: http://www.unesco.org.br/areas/dsocial/ destaques/progabrindoespacos/escolaabertacidadaniargs/mostra_documento. Acesso em: 20 maio 2008.
O jornal Zero Hora, de ampla circulação no Rio Grande do Sul, cumpre sua parte, divulgando a eficácia desse programa na redução da violência escolar. Na foto publicada para ilustrar a matéria, aparecem crianças entrando na escola, em cujo portão há uma imensa faixa proclamando "Esta é uma Escola Aberta para a cidadania”. Junto à foto está a chamada “A escola que voltou a sorrir”; a legenda anuncia que se vive um clima de paz após um mês em que uma mãe havia sido surrada por alunos (ver figura 3, a seguir):

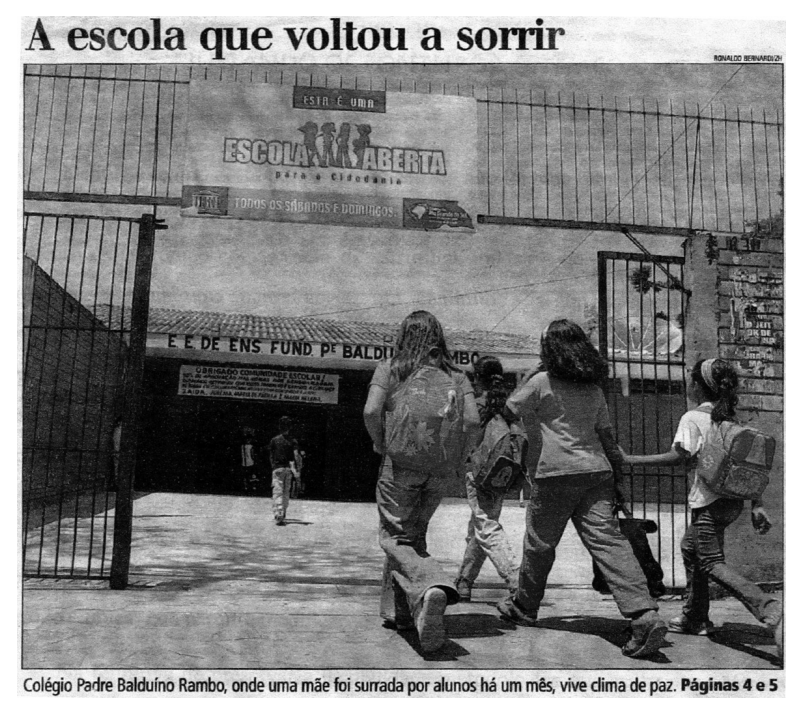

Figura 3: Matéria em jornal sobre resultados do programa Escola Aberta (Zero Hora, 25 out. 2003, segunda capa)

Evidencia-se assim a cultura utilizada não só para “resolver” determinadas disfunções sociais, mas, principalmente, para administrar populações. ${ }^{16}$ É nesse sentido que o projeto Você Apita de certa forma tam-

${ }^{16}$ Uma interessante evidência disso é a iniciativa do governo da província de Cebu, nas Filipinas - amplamente divulgada pela mídia mundial -, que introduziu a dança como atividade para centenas de prisioneiros de um centro de detenção e reabilitação. Os resultados indicam que a nova rotina de exercícios melhorou “drasticamente” o comportamento dos presos. Os detentos já dançaram ao som de In The Navy e YMCA, do Village People, e outras coreografias estão sendo ensaiadas, além do sucesso de Vanilla Ice. 
bém sugere que cada escola busque a performatividade para praticar o "social", o que significa, por exemplo, que cada escola seja instigada a compor suas redes de relações com jornais, ONGs, empresas, associações de moradores etc., visando a ações sociais orientadas para a solidariedade e para a promoção da cidadania responsável.

Os três projetos escolhidos para nossa análise têm como alvo populações pobres, alunos de escolas públicas de periferia e suas famílias. Ou seja, parece que são essas populações que precisam ser rápida e satisfatoriamente gerenciadas por meio de projetos culturais com vistas, por exemplo, a garantir que os alunos fiquem longe do mundo do crime mediante participação em atividades culturais no ambiente da escola nos finais de semana, períodos em que, segundo pesquisas, ${ }^{17}$ há concentração de ações violentas. Esse é o caso do programa Escola Aberta, que foi capaz de potencializar - oportunizando atividades culturais nos finais de semana - o espaço escolar no governamento da vida de grande parte da população pobre que o frequenta.

Constata-se, então, que ações de educação para a cidadania, antes consideradas obrigação do Estado, principal encarregado de prover políticas dirigidas à regulação das desigualdades com vistas à socialização e à integração da nação, passam agora a fazer parte de programas compartilhados de gestão, nos quais interesses do Estado se mesclam com ações sociais inequivocamente marcadas por interesses de mercado, assim como a construção do Museu Guggenheim em Bilbao, projetado pelo mundialmente conhecido arquiteto Frank Gehry, tem sido celebrada como iniciativa revitalizadora que transformou em pólo turístico uma cidade outrora assolada por problemas de várias naturezas. ${ }^{18} \mathrm{E}$ assim como Miami, antes

${ }^{17}$ Segundo reportagem do jornal Zero Hora, de 21 mar. 2006, "Pesquisa da Unesco indica que a maior parte das ações violentas envolvendo jovens ocorre nos finais de semana" (p. 30).

${ }^{18}$ De acordo com Yúdice (2004), o Guggenheim de Bilbao encaixa-se nas novas formas de desenvolvimento urbano em que são mobilizados rituais e práticas estéticas do dia a dia com a rotulada como culturalmente estagnada e socialmente tensa, por sua hoje decantada vocação multicultural está sendo crescentemente considerada uma metrópole cultural, tornando-se um centro de "produção para as indústrias da cultura” (Yúdice, 2004, p. 281); de forma similar, e consideradas as devidas proporções, o Escola Aberta transformou escolas em polo cultural para as populações pobres e em oportunidade com potencial econômico para muitas pessoas dessas comunidades. A visibilização dos efeitos desse programa é providenciada, e a comemoração dos resultados é matéria de jornal.

\footnotetext{
De apenas uma mãe curiosa, no primeiro final de semana, o número de participantes da Escola Aberta para a Cidadania no Colégio José do Patrocínio, no bairro Restinga Velha, evoluiu para 6 mil pessoas todos os meses. É um exemplo dos resultados obtidos pelo projeto no Estado, implantado em agosto de 2003. (Zero Hora, 21 mar. 2006, p. 30)
}

Isso significa que, se a escola estava acostumada a receber pouquíssimas pessoas em atividades mais diretamente relacionadas ao "pedagógico”, como reunião de pais, entrega de avaliações etc. - que acontecem em horários, turnos e datas variadas, incluindo os sábados - e isso poderia, inclusive, ser entendido como iniciativa de uma escola com problemas, agora ela parece "encontrar" o seu lugar como copromotora de um certo tipo de cidadania cultural e trazer “multidões” para o seu espaço. São populações sedentas por usufruir e participar da cultura em um mundo em que a cultura é cada vez mais central, espetáculo de visibilidades, e, como diz Yúdice (2004), performativa. No Escola Aberta cria-se um espaço para a promoção de iniciativas culturais de todo tipo, com destaque àquelas em que as pessoas se engajam em atividades, compartilham experiências e atualizam saberes. Revitaliza-se também a economia local, uma vez que pessoas antes excluídas do universo produtivo são contratadas pelo programa para

finalidade de promover o turismo e as indústrias do patrimônio (museus, feiras culturais, festivais gastronômicos etc.). 
ministrar oficinas nos finais de semana no espaço físico da escola. Tais oficinas - classificadas como culturais (percussão, bandas, cultura afro, danças folclóricas, grafite, pagode, dança de salão, teatro etc.), artesanais/geração de renda (arranjos para festas, bijuterias, bordado, crochê, biscuit, fuxico, artes plásticas, horta, modelo/manequim, padaria, reciclagem, beleza/cabeleireiro etc.), esportivas (capoeira, futebol, xadrez, biodança, hip-hop, skate, caminhadas, atletismo, atividades recreativas etc.) e pedagógicas (culinária, informática, rádio estudantil, reforço escolar, ecoturismo, celebrações religiosas, palestras etc. $)^{19}$ - são realizadas preferencialmente por pessoas da comunidade escolar, ao mesmo tempo em que são estabelecidas parcerias com ONGs, universidades, associações e entidades da sociedade civil, organizações estatais e organismos internacionais. Em 2003, no Rio Grande do Sul, por exemplo, participaram do programa a Aracruz Celulose S.A., a Gerdau Aços Longos S.A. e a Companhia Estadual de Energia Elétrica (CEEE), entre outras.

A performatividade está também aí e a conveniência da escola é facilmente perceptível, seja para a visibilização dos “benfeitores sociais”, que acumulam capital simbólico e valorizam seus produtos e empreendimentos, revelando-se engajados na promoção do bem-estar dessas populações, seja para realizar a "venda” de experiências humanas ${ }^{20}$, seja para oportunizar ações de coordenação social, de governo das populações, agora sob a égide do poder cultural, entendido

${ }^{19}$ As oficinas relacionadas foram realizadas no âmbito do programa Escola Aberta no Rio Grande do Sul, durante o ano 2003. Disponível em: http://www.educacao.rs.gov.br/pse/html/ escola_aberta.jsp?ACAO=acao1. Acesso em: 22 maio 2008.

${ }^{20}$ Yúdice (2004, p. 266) comenta que a economia da manufatura e da comercialização de mercadorias vem ocupando lugar secundário no que se refere à cultura. Na nova etapa do capitalismo, a economia cultural tem sido definida cada vez mais pela "compra e venda de experiências humanas”, seja em centros turísticos de entretenimento, em cidades temáticas, em shoppings centers, na moda, no cinema, na televisão ou no mundo virtual. por Yúdice (2004) como extensão do biopoder ${ }^{21}$ em tempos de globalização.

Embora o programa Escola Aberta seja uma iniciativa governamental - fruto de um acordo entre o Ministério da Educação e a Organização das Nações Unidas para a Educação, a Ciência e a Cultura (UNESCO) -, cabe considerar que, se antes era o Estado quem investia e gerenciava a cultura, na atualidade, com o fim da condição de Estado benfeitor, ele não precisa ser necessariamente o principal “responsável” pela cultura, repartindo com a sociedade civil tal incumbência. E, como argumenta Yúdice (2004), “a tática de reduzir as despesas estatais, que pode parecer a sentença de morte das atividades artísticas e culturais sem fins lucrativos, é, na verdade, sua condição de possibilidade" (p. 29). Quer dizer, instigantes arranjos se desenham em parcerias de setores distintos da sociedade para, de certa forma, "suprir” o vazio deixado pelo Estado e, por outro lado, contrastar a criticada inoperância deste com a "performatividade" que, conclamadamente, caracterizaria as iniciativas das organizações privadas. Robertson (2006e, p. 65) corrobora essa percepção ao sublinhar que a retórica de que "o que conta é aquilo que funciona!” tem sido enfaticamente associada às atuações da Terceira Via, numa clara alusão ao fato de que apenas o setor privado é capaz de fazer as coisas funcionarem de forma eficiente e eficaz.

Isso pode ser constatado também no projeto Você Apita, em que é criada uma extensa e variada rede de colaboradores (no ano de 2003, somavam 456 integrantes, desde organismos locais até internacionais) em cada cidade na qual o projeto é desenvolvido. Tal rede "une”, por exemplo, jornais a grandes empresas, a igrejas, a associações, a policiamento, a secretarias de Educação, a escolas etc. O que parece ligar setores tão distintos e por vezes antagônicos da sociedade são

\footnotetext{
${ }^{21}$ Um poder que se organiza e é exercido sobre a vida com a
} finalidade de governar e gerir a população. O biopoder foi elemento indispensável para o desenvolvimento do capitalismo, garantindo a inserção controlada dos corpos no aparato produtivo e o ajuste dos fenômenos populacionais aos processos econômicos (Foucault 1999, 2001; Castro, 2004). 
propósitos comuns (e provisórios) no gerenciamento da cultura. "É por haver um [ou vários] propósito[s] que se torna possível falar de cultura como recurso" (Yúdice, 2004, p. 63). Provavelmente tais uniões não devem durar muito mais do que a contingência e a efemeridade do que circunstancialmente as reuniu. Segundo Bauman (2003), diferentemente do passado, em que a ideia de comunidade nos ligava às mesmas pessoas, grupos e instituições durante um longo tempo, na atualidade, estar em uma "comunidade" (que pode ser uma rede de colaboradores) significa estar unido hoje a alguns, amanhã a outros, e depois a outros mais. Ou seja, de acordo com Yúdice (2004), na performatividade muitos princípios de inclusão e exclusão se encontram em disputa, e é isso que permite que entidades e organismos com propósitos tão distintos (ou nem tanto?) se unam temporariamente com propósitos comuns. No projeto Você Apita, em que não se procura instaurar diretamente uma visão específica de mundo, a estratégia é "reunir as pessoas para que elas possam negociar suas diferenças e encontrar um denominador comum, ou seja, colocar parâmetros para coordenar a mudança social” (Yúdice, 2004, p. 206). Ao mesmo tempo, temos, como bem argumenta Bauman (2001), a ilusão de compartilhar, que não dura muito mais do que o tempo de uma performance.

Além disso, essas uniões geram uma força performativa que permite não uma ação frontal contra um único foco problemático, mas uma gama de ações operadas por diferentes grupos e organizações. No Você Apita, os alunos de uma única escola participaram de atividades que envolviam desde questões relacionadas à problemática da preservação do meio ambiente (como a participação na palestra sobre o uso racional dos recursos hídricos, proferida pelo vice-presidente da Associação Nacional dos Serviços Municipais de Saneamento) até questões relacionadas, por exemplo, com as diferenças que implicam necessidades especiais ("Escolas de Porto Alegre recebem cadeirante para discutir mobilidade”22) e com a política (“Alunos

22 Disponível em: http://www.voceapita.com.br/. Acesso em: 21 maio 2008. de Porto Alegre participaram de encontro sobre liderança juvenil em Canela”²3).

Ao mesmo tempo em que essas redes garantem distintas ações, elas também asseguram que, por meio delas, as marcas das empresas estejam presentes em muitas frentes. No projeto Você Apita, além das diversas parcerias com instituições não governamentais e governamentais, a parceria específica com diferentes mídias se encarregou de divulgar, local e nacionalmente, as ações realizadas dentro do projeto, enfatizando a constante presença da marca Fiat na educação, bem como a marca dos outros apoiadores em cada ação realizada. "Senac realiza amanhã projeto Você Apita” (Cruzeiro do Sul, 4 ago. 2004), "UNESCO reconhece trabalho” (O Pioneiro, 5 fev. 2004), "Projeto Você Apita inicia atividades” (Diário do Nordeste, 26 nov. 2003) são algumas das notícias ${ }^{24}$ referentes ao projeto que colocam em circulação os logotipos dos participantes e disseminam a imagem de que estão comprometidos com a responsabilidade social ao participar, promover e custear atividades educativas.

No horizonte dessa movimentação está sempre a performatividade. Como ressaltou Robertson (2006e), a retórica “o que conta é aquilo que funciona!” é recorrentemente fortalecida. O projeto Você Apita não só monta uma rede de colaboradores, como sugere e ensina como cada escola pode e deve proceder para formar a sua própria rede:

\section{Como formar uma rede de colaboradores?}

Para formar a rede, inicialmente é importante fazer o levantamento das organizações existentes no entorno da escola, tais como associações de bairro, grupos de jovens, ONGs, postos comunitários. Em seguida, é interessante visitar órgãos governamentais como subprefeituras, coordenadorias, regionais, prefeitura, secretarias e convidá-los a participar da rede, seja por meio de palestras, debates, fornecimento

${ }^{23}$ Disponível em: http://www.voceapita.com.br/. Acesso em: 21 maio 2008.

${ }^{24}$ Estes dados foram coletados no site do Você Apita. Assim, a inclusão dessas notícias no site constitui mais uma modalidade de divulgação das repercussões do projeto. 
de materiais ou até mesmo da implementação de uma ação. As universidades também podem contribuir bastante em diversas áreas. O contato com estas organizações pode ser por e-mail, telefone ou visitas pré-agendadas. É importante, sempre, esclarecer primeiro o que é o Você Apita e que tipo de colaboração daquela pessoa ou instituição se deseja. Deixar o colaborador livre para propor ideias e formas de participação também é fundamental. Todas as organizações e pessoas que se prontificarem a participar como colaboradores devem ser cadastradas, com todos os dados de identificação e formas de atuação. É possível saber mais sobre o assunto, consultando a detalhada explicação que está na primeira ficha de atividade. ${ }^{25}$

É assim que o projeto Você Apita sugere que cada escola "busque" a performatividade para praticar o "social". Ele recomenda, por exemplo, que cada escola componha suas redes de relações com jornais, ONGs, empresas, associações de moradores etc. É alertado que tudo isso, porém, seja feito sem imposições. Conforme se lê - "deixar o colaborador livre para propor ideias e formas de participação também é fundamental". Isso significa que, em vez de querer instaurar sua visão de mundo ou buscar a mudança das estruturas sociais, se recomenda que a escola opere, de certa forma, como uma "poliglota da sociabilidade”. Essa expressão, segundo Yúdice (2004), foi cunhada por Rubem Fernandes para referir-se à "habilidade de se engajar com uma multiplicidade de linguagens, de códigos simbólicos e de formas sociais e culturais” (Fernandes apud Yúdice, 2004, p. 206) em uma sociedade plural. Nesse tipo de sociedade, para ter sucesso é necessário "falar” múltiplas linguagens, negociar as diferenças e encontrar denominadores comuns, mesmo que provisórios,

${ }^{25}$ Estas informações estão localizadas no site do projeto Você Apita, em um espaço intitulado Tira dúvidas, sugerindo que, efetivamente, os membros das escolas desempenhem a função de "poliglotas da sociabilidade” (termo cunhado por José Júnior, diretor do Grupo Cultural Afro Reggae e referido por Yúdice, 2004). Disponível em: http://www.voceapita.com.br/tira_duvidas. asp. Acesso em: 12 fev. 2008. para coordenar a mudança social (Yúdice, 2004). E ele explica:

ao invés de uma ação frontal contra uma única fonte de opressão, convém que se opere com uma gama de grupos e organizações, trabalhando com as interfaces e intermediando sua articulação entre as diversas agendas, digamos as de um grupo de bairro junto a uma igreja, um governo local, uma ONG nacional ou regional, e junto às fundações internacionais. (Yúdice, 2004, p. 215)

Em suas investigações, Yúdice (2004) analisa o projeto AfroReggae, demonstrando uma série de movimentos realizados por seus integrantes na composição de redes visando ao gerenciamento da cultura. De certa forma, o autor faz pensar que a lógica utilizada pelo AfroReggae (e aqui podemos pensar na lógica do Você Apita) é a mesma praticada por grandes empresas que buscam o acúmulo de capital (simbólico, cultural, financeiro, social). Assim, a lógica parece ser a mesma, uma vez que, como já afirmamos, a performatividade tem sido o modo pelo qual cada vez mais o social é praticado. O que parece diferir são os propósitos, seja do AfroReggae, do Você Apita ou de uma grande corporação.

\section{Um outro "uso" para a escola?}

Nosso objetivo neste artigo foi procurar mostrar um outro "uso" para a escola, atrelado à lógica do atual estágio da globalização em que a cultura ocupa uma posição singularmente importante, entremeando-se na vida social, nos circuitos econômicos e regimes políticos.

Quase todos nós temos na memória o registro de algum episódio em que empresas utilizam as práticas e os espaços escolares para divulgar seus produtos. Lembramos aqui das fábricas de refrigerantes que, de vez em quando, apareciam distribuindo gratuitamente a bebida junto com brindes que levavam suas marcas. Tratava-se, contudo, de táticas com fins explicitamente comerciais: mostrar e divulgar para conquistar novos consumidores. 
Parece que hoje é diferente, pois os usos contemporâneos da cultura implicam "ações” estratégicas de instituições com poder simbólico consolidado, como a escola. A "conveniência” da escola na era global, como procuramos demonstrar, ultrapassa simples pretensões mercantis. Embora estas persistam embutidas nas novas negociações, os objetivos hoje são amplos, diversificados e visam bem mais do que vender produtos. O que está em jogo é a possibilidade de inscrever a imagem das empresas na alma das pessoas (Klein, 2004), tão indelevelmente que elas passam a governar não apenas suas vidas (e aqui pensamos em gosto, preferências, posições políticas, formas de sensibilidade, estilos, condutas, escolhas...), arregimentando-as em seus exércitos corporativos de consumidores globais, mas também ajudam a forjar suas visões de mundo e de sociedade. Aliar-se a projetos sociais com propósitos democráticos edificantes contribui para posicionar os megaconglomerados mercantis da atualidade em um território protegido, sancionado pela sociedade. A cultura é sua poderosa aliada e a escola é um de seus espaços preferenciais, especialmente porque confere legitimidade e a tarja de "boas intenções” às suas iniciativas. Com credibilidade e com projetos “culturais” em que a benevolência social sempre está contemplada, mesmo que minimamente, a gestão do capital - e da vida - prossegue de vento em popa.

E, para sermos consistentes em relação ao autor que nos forneceu as ferramentas conceituais para esta análise, devemos sublinhar que, em seu trabalho como professor e pesquisador, George Yúdice tem investido esforços no sentido de encontrar formas de participação na gestão cultural que carreiem benefícios para a melhoria da vida das populações menos aquinhoadas do planeta. Os usos da cultura demonstram que ela é uma ferramenta para objetivos diversificados e, assim, um valioso recurso também para contestações e para uma enorme variedade de propósitos sociopolíticos e econômicos. Como uma nova ordem está em vigor, um dos desafios consiste em engajar-se em permanentes táticas de decifração das lógicas que circunscrevem e coordenam nossas vidas. Esse é um deles, mas não o único.

\section{Referências bibliográficas}

ARROYO, Miguel. A escola é importantíssima na lógica do direito à educação básica. In: COSTA, Marisa Vorraber. A escola tem futuro? 2. ed. Rio de Janeiro: Lamparina, 2007. p. 119-149.

BAUMAN, Zigmunt. Modernidade líquida. Trad. Plínio Dentzien. Rio de Janeiro: Jorge Zahar, 2001.

. Comunidade: a busca por segurança no mundo atual.

Trad. Plínio Dentzien. Rio de Janeiro: Jorge Zahar, 2003.

CASTRO, Edgardo. El vocabulário de Michel Foucault. Bernal: Universidad Nacional de Quilmes, 2004.

COSTA, Marisa Vorraber. A escola tem futuro? 2. ed. Rio de Janeiro: Lamparina, 2007a.

A escola rouba a cena. In: Aescola tem futuro?

2. ed. Rio de Janeiro: Lamparina, 2007b. p. 11-22.

FISCHMAN, Gustavo E. Ni Publica, ni Privada ¡Comercializada! A Página da Educação, v. 13, n. 137, p. 28, ago./set. 2004. .; COSTA, Ricardo Jorge. Entrevista. A sociedade americana vê a educação pública em estado de crise terminal. A Página da Educação, v. 13, n. 138, p. 11, out. 2004.

FOUCAULT, Michel. Aula de 17 de março de 1976. In: Em defesa da sociedade. São Paulo: Martins Fontes, 1999. p. 285-315. Direito de morte e poder sobre a vida. In:

História da sexualidade, v. 1 - A vontade de saber. Rio de Janeiro: Graal, 2001. p. 126-137.

GERZSON, Vera Serezer. Amídia como dispositivo da governamentalidade neoliberal - os discursos sobre educação nas revistas Veja, Época e IstoÉ. Tese (Doutorado em Educação) - Faculdade de Educação, Universidade Federal do Rio Grande do Sul, Porto Alegre, 2007.

JAMESON, Fredric. Pós-Modernismo. A lógica cultural do capitalismo tardio. Trad. Maria Elisa Cevasco e rev. Iná Camargo Costa. São Paulo: Ática, 1996.

KLEIN, Naomi. Sem Logo - A tirania das marcas em um planeta vendido. 4. ed. Trad. Ryta Vinagre. Rio de Janeiro: Record, 2004.

KRAWCZYK, Nora Rut. Políticas de regulação e mercantilização da educação: socialização para uma nova cidadania. Educação \& Sociedade, v. 26, n. 92, p. 799-819, out. 2005.

MOREIRA, Antônio Flávio Barbosa. A escola poderia avançar um pouco no sentido de melhorar a dor de tanta gente. In: COSTA, Marisa Vorraber. A escola tem futuro? 2. ed. Rio de Janeiro: Lamparina, 2007. p. 51-76.

ROBERTSON, Susan. Acabemos com a pobreza e com o perdão da dívida: agora as crianças do mundo podem ir à escola. In: MAGA- 
LHÃES, António M.; STOER, Stephen R. (Orgs.). Reconfigurações: educação, Estado e cultura numa época de globalização. Porto: Profedições, 2006a. p. 85-87.

. Ideias, ideias, ideias: marca a tua posição! Sê um cidadão empreendedor na batalha da tua nação na economia global. In: MAGALHÃES, António M.; STOER, Stephen R. (Orgs.). Reconfigurações: educação, Estado e cultura numa época de globalização. Porto: Profedições, 2006b. p. 81-83.

. É o teu cérebro que nós queremos: a bala de prata da sociedade do conhecimento. In: MAGALHÃES, António M.; STOER, Stephen R. (Orgs.). Reconfigurações: educação, Estado e cultura numa época de globalização. Porto: Profedições, 2006c. p. 73-75. . Iludindo e configurando a economia do conhecimento. In: MAGALHÃES, António M.; STOER, Stephen R. (Orgs.). Reconfigurações: educação, Estado e cultura numa época de globalização. Porto: Profedições, 2006d. p. 69-72.

Soluções sinergéticas ou monstros híbridos: educação modernizadora pela via das parcerias público-privadas. In: MAGALHÃES, António M.; STOER, Stephen R. (Orgs.). Reconfigurações: educação, Estado e cultura numa época de globalização. Porto: Profedições, 2006e. p. 65-67.

. Levando as diásporas ao mercado: erguendo o talento (e o patriotismo) nas economias nacionais. A Página da Educação, v. 16 , n. 171 , p. 12 , out. 2007a.

. Tecno-aprendizagem, nações inteligentes e o futuro.

A Página da Educação, v. 16, n. 164, p. 11, fev. 2007b.

VEIGA-NETO, Alfredo. Pensar a escola como uma instituição que pelo menos garanta a manutenção das conquistas fundamentais da Modernidade. In: COSTA, Marisa Vorraber. A escola tem futuro? 2. ed. Rio de Janeiro: Lamparina, 2007. p. 97-118.

YÚDICE, George. A conveniência da cultura: usos da cultura na era global. Trad. Marie-Anne Kremer. Belo Horizonte: Editora UFMG, 2004.

. Economia auto-sustentável. Entrevista a Heloisa Buarque de Hollanda, 2005. Disponível em: <http://portalliteral. terra.com.br/Literal/calandra.nsf/0/32E954AD22E891A5032570
58006DDC4B?OpenDocument\&pub=T\&proj=Literal\&sec=Dial ogos>.

. Cultura e educação no novo entorno. In: SOMMER, Luís Henrique; BUJES, Maria Isabel (Orgs.). Educação e cultura contemporânea: articulações, provocações e transgressões em novas paisagens. Canoas: Ed. ULBRA, 2006. p. 11-21.

MARISA VORRABER COSTA, doutora em educação pela Universidade Federal do Rio Grande do Sul (UFRGS), é professora dos Programas de Pós-Graduação em Educação da UFRGS e da Universidade Luterana do Brasil (ULBRA). Publicações recentes: A escola tem futuro? (2. ed. Rio de Janeiro: Lamparina, 2007); O magistério na política cultural (Canoas: Ed. ULBRA, 2006) e Educação na cultura da mídia e do consumo (Rio de Janeiro: Lamparina, 2009). Pesquisa em andamento: “Consumo, mídia e espetáculo na cena pedagógica - investigando relações entre escola e cultura contemporânea”.E-mail: mcvorraber@terra.com.br

MARIANGELA MOMO, doutora em educação pela Universidade Federal do Rio Grande do Sul (UFRGS), é professora adjunta do Departamento de Educação da Universidade Federal do Rio Grande do Norte (UFRN). Publicações recentes: Mídia e consumo na produção de uma infância pós-moderna que vai à escola (Tese (Doutorado em Educação), Universidade Federal do Rio Grande do Sul, Porto Alegre, 2007); Para se pensar a globalização da infância e da juventude escolar - um olhar sobre o consumo, em coautoria com COSTA, Marisa Vorraber (In: PEREIRA, Maria Zuleide da Costa; CARVALHO, Maria Eulina Pessoa de; PORTO, Rita de Cássia Cavalcanti (Orgs.). Globalização, interculturalidade e currículo na cena escolar. Campinas: Átomo-Alínea, 2009. p. 207224). Pesquisa em andamento: "Mídia, consumo e culturas locais na produção de sujeitos infantis em escolas de educação infantil na grande Natal/RN”.E-mail: marimomo@terra.com.br

Recebido em agosto de 2008 Aprovado em maio de 2009 
Key words: representations of masculinity; teaching of Physics; research activities.

\section{Representaciones de masculinidades latentes en clases de física de la escuela secundaria}

El estudio caracteriza aspectos latentes de masculinidades que traen implicaciones para el aprendizaje individual y colectivo de una clase de la escuela secundaria. Clases de física del primer año de una escuela secundaria fueron acompañadas a lo largo de un año. A microanálisis de una secuencia de seis clasesgravadas en audio y en videoenvolviendo una actividad que simula el trabajo de una comunidad científica, caracteriza las interacciones predominantes entre los jóvenes. Las masculinidades destacadas se movilizan en torno del estímulo frente a situaciones desafiantes y de competición, de la curiosidad por el fenómeno investigado, del desafío a las reglas establecidas en la conducción de la actividad. Entre las implicaciones del estudio, se destaca la necesidad de tener en cuenta las manifestaciones de masculinidades que puedan comprometer el desarrollo de las actividades en la clase y el funcionamiento de los grupos de aprendizaje.

Palabras claves: representaciones de masculinidad; enseñanza de física; actividades investigadoras.

Marisa Vorraber Costa e Mariangela Momo

\section{Sobre a "conveniência” da escola}

O artigo pretende mostrar um novo “uso” para a escola, atrelado à lógica do atual estágio da globalização, em que a cultura ocupa uma posição singularmente importante, entremeando-se na vida social, nos circuitos econômicos e regimes políticos. Recorrendo à teorização de George Yúdice sobre os usos da cultura na era global, são analisados três projetos sociais - Você Apita, Tim Música nas Escolas e Escola Aberta - considerados expressivos da forma como empresas, organizações públicas e iniciativas da sociedade civil se articulam com a cultura e a educação para fazer os mercados globalizados se movimentarem, mas não apenas em seus próprios interesses, embora esses persistam no topo das prioridades. Há indícios de que a “conveniência” da escola ultrapassa o interesse mercantil imediato e se projeta como estratégia direcionada a uma variada gama de propósitos sociopolíticos, econômicos e culturais, entre eles a possibilidade de governar a vida das pessoas, forjando visões de mundo e de sociedade.

Palavras-chave: escola e globalização; escola e cultura; governamento; projetos sociais; biopolítica.

On the "convenience" of school This article aims at showing a new "use" for school that is linked to the logic of the current stage of globalization, in which culture occupies a uniquely important position, interwoven with social life, economic circuits and political regimes. Making use of George Yúdice's theorization about the uses of culture in the global era, three social projects are analyzed - Você Apita, Tim Música nas Escolas and Escola Aberta. These projects are considered expressive of the way in which businesses, public entities and civil society initiatives are articulated with both culture and education in order to make globalized markets move, but not only favouring their own interests, although these remain as top priorities. Evidence exists that the "convenience" of school outweighs the immediate business interest and projects itself as a strategy directed towards a wide range of social-political, economic and cultural purposes. Among them is the possibility of governing people's lives, forging both world and societal views.

Key words: school and globalization; school and culture; government; social projects; bio-politics.

Sobre la "conveniencia" de la escuela El artículo pretende mostrar un nuevo “uso" para la escuela, vinculado a la lógica de la etapa actual de la globalización en la que la cultura ocupa una posición singularmente importante, entrelazándose en la vida social, en los circuitos económicos y en los regímenes políticos. Recurriendo a la teorización de George Yúdice sobre los usos de la cultura en la era global, se analizan tres proyectos sociales Você Apita, Tim Música nas Escolas y Escola Aberta - considerados expresivos de la forma como empresas, organizaciones públicas e iniciativas de la sociedad civil se articulan con la cultura y con la educación para hacer con que los mercados globalizados se muevan, pero no sólo en sus propios intereses, aunque ellos persistan en la cima de las prioridades. Hay indicios de que la "conveniencia" de la escuela sobrepasa el interés mercantil inmediato, y se proyecta como estrategia dirigida hacia una variada gama de propósitos socio-politicos, económicos y culturales. Entre ellos, la posibilidad de gobernar la vida de las personas, forjando visiones de mundo y de sociedad.

Palabras claves: escuela y globalización; escuela y cultura; gobierno; proyectos sociales; biopolítica.

Ana Lúcia Felix dos Santos e Janete Lins de Azevedo

A pós-graduação no Brasil, a pesquisa em educação e os estudos sobre a política educacional: os contornos da constituição de um campo acadêmico

Este artigo problematiza especificidades que cercam o campo acadêmico da 